\title{
Impact of the Coastal Management Program to Community Residents
}

\author{
Mauro Allan P. Amparado \\ Director, Community Awareness, Relations \& \\ Extension Services \\ mapamparado@gmail.com
}

\begin{abstract}
Niño L. Lumanta
Program CARES Coordinator, College of Marine Engineering
\end{abstract}

Ronelio I. Tisoy

Program CARES Coordinator, College of Marine

Transportation

\section{University of Cebu Lapu-Lapu \& Mandaue, Mandaue City, Cebu, Philippines}

\begin{abstract}
This study ascertained the impact of the coastal management program implemented by a university in Village Looc, Mandaue City, Cebu, Philippines. The findings served as basis for program enhancement. This qualitative study utilized the descriptive design. It was conducted in Village Looc, Mandaue City, Cebu, Philippines. There were ten informants who were interviewed six months after the implementation of the coastal management program in April 2019. The coastal management program was called Save the Barangay (Village) Looc Mandaue City Bay. This coastal management program is a joint collaboration program between the Village Looc Council and UCLM. The researchers interviewed the informants for four consecutive Saturdays. Common themes were ascertained from the narratives of the informants.
\end{abstract}


The study revealed four common themes: Garbage directly thrown at sea; The sea as comfort room; Coastal Management Program is helping our environment; and Clamor to extend the coastal management program.

From the secondary data collected from UCLM, a total of 11,290 kilos of solid wastes were collected from April 2019 to January 2020. The residents were satisfied with the program and find this beneficial to their village. The residents are also yearning for the extension of the program.

Keywords: Coastal Management Program; Impact; Garbage; Solid wastes; Mandaue City, Cebu, Philippines

Recommended citation: Amparado, M. A. P., Lumanta, N. L. \& Tisoy, R. I. (2020). Impact of the Coastal Management Program to Community Residents. Cebu Journal of Maritime Education, 1(1), 88-100.

\section{Introduction}

The coastal waters of Southeast Asian countries have some of the world's richest ecosystems characterized by extensive coral reefs and mangrove forests. Blessed with warm tropical climate and high rainfall, these waters are further enriched with nutrients from land which enable them to support a wide diversity of marine life. it supports marine life and human life as well. Because economic benefits could be derived from them, the coastal zones in these countries teem with human settlements. Over $70 \%$ of the population in the region lives in coastal areas which are characterized by high-level resource exploitation brought about by increasing population pressure and associated economic activities over the last two decades. Large-scale destruction of the region's valuable resources has caused serious degradation of the environment, thus affecting the economic condition and quality of 
life of the coastal inhabitants. This lamentable situation is mainly the result of ineffective or poor management of the coastal resources (Pauly, 1989).

This scenario was observed in Village Looc, Mandaue City, the partner community of University of Cebu Lapu-Lapu and Mandaue located in Mandaue City, Cebu, Philippines. The informal settlers have built structures on the coastal area which serves as their homes. This has affected the conditions of the area inasmuch as garbage and human fecal matter are directly disposed in the area.

The deteriorating conditions of the coastal area have been raised in the regular meetings of the village council and posted in social media by concerned individuals. The situation has also prompted the village officials to seek for the assistance of UCLM to help the village in the rehabilitation of the coastal area.

With garbage and fecal matter as sources of wastes, the need for coastal management was very evident in an investigation made by Amparado, Camayra, Dorio \& Patindol (2017). Determining the community profile is essential to strategically implement sustainable programs for the partner community. In its 8th year of implementing community extension activities, this university reassesses the community profile of the village to ensure that the programs are timely and on par with the needs of community residents. Data collected in 2008 and 2016 were compared utilizing descriptive quantitative design. In 2008, community extension programs were focused on solid waste management, literacy, and livelihood programs. The survey in 2016 identified sustainable programs for the university which includes solid waste management, health education, literacy, livelihood, greening, livestock raising and community participation programs. 
Village Opao which is beside Village Looc is also a coastal community. The conditions of other communities also affect the coastal situation of Village Looc. In the study of Amparado \& Colonia, they also presented that the problems of the village include drainage problems, flooding, garbage, employment, and road repairs (2020).

Social Responsibility adds an ethical imperative to do those things that make society better and not to do those that could make it worse. A socially responsible organization goes beyond what it must do by law or chooses to do only because it makes economic sense to doing what it can to help improve society because that's the right, or ethical, thing to do. Social responsibility requires business to determine what is right or wrong and to make ethical decisions and engage in ethical business activities. A socially responsible organization does what is right because it has an obligation to act that way. On the other hand, social responsiveness refers to the capacity of a firm to adapt to changing societal conditions. The idea of social responsiveness stresses that managers make practical decisions about the societal actions in which they engage. A socially responsive organization acts the way it does because of its desire to satisfy some expressed social need. Social responsiveness is guided by social norms. The value of social norms is that they can provide managers with a meaningful guide for decision making (Robbins \& Coulter, 2001).

\section{Related Studies}

Various studies have been conducted on coastal clean-up and coastal management programs. In the research of Wyles, Pahl, Holland \& Thompson, they cited that coastal visits not only provide psychological benefits but can also contribute to the accumulation of rubbish. Volunteer beach cleans help address this issue, but may only have limited, local impact. Consequently, it is important to study any broader benefits associated with beach 
cleans. This article examines the well-being and educational value of beach cleans, as well as their impacts on individuals' behavioral intentions. We conducted an experimental study that allocated students $(n=90)$ to a beach cleaning, rock pooling, or walking activity. All three coastal activities were associated with positive mood and pro-environmental intentions. Beach cleaning and rock pooling were associated with higher marine awareness. The unique impacts of beach cleaning were that they were rated as most meaningful but linked to lower restorativeness ratings of the environment compared with the other activities. This research highlights the interplay between environment and activities, raising questions for future research on the complexities of personenvironment interactions (2017).

Amparado, Pinote \& Hinoguin revealed in their study that there were five corporate social responsibility activities that were usually conducted by MBA students in their respective organizations which includes: visiting the home for the aged and orphanage; solid waste management; coastal clean-up; tree planting; and feeding program. Informants narrated that the benefits of conducting corporate social responsibility activities were: better image of the company; protection of environment; and sharing of knowledge and skills to beneficiaries. However, the challenges they encountered includes: monetary/budget issues; less participation from colleagues; and conflict with other organizational responsibilities.

Perez \& Cabrera conducted a study on the impact of coastal clean-up to beneficiaries and proponents (2013). The beneficiaries perceived the program design as highly effective in developing an agenda on participatory coastal management, conserving the environment and has the potential to lessen the risks of acquiring diseases while less effective in providing opportunities for extra income. On the assessment of the proponents, the program is highly effective in promoting sanitation and cleanliness and in 
ensuring safe and sure delivery of service with its aim of conserving the environment while less effective in providing opportunities for extra income. The beneficiaries strongly agreed that they understood the results the drive could bring upon them and that they have learned the part or role they have to do in this problem. The program provided them the skill of recycling their own garbage thus, urged them to become more disciplined. On the part of the proponents, they strongly agreed that they gained better understanding about the law and policy about coastal environment preservation and understood the results the drive could bring upon them. Further, the program gave way to empower themselves to create beautification projects for the community and made them realize they have to set good examples for others.

In another study, it examined factors influencing the sustainability of integrated coastal management (ICM) projects in the Philippines and Indonesia. Measures of project sustainability are developed and primary data collected at the village level are analyzed to determine the effects of project activities and individual characteristics on ICM sustainability. The findings indicate that perceptions of benefits as well as initial benefits influence early involvement and participation in the ICM projects evaluated in the Philippines and Indonesia. In turn, this involvement enhances the chances that ultimate benefits will be those desired by the target population. Finally, achievement of these benefits stimulates continuing involvement in the activities, sustaining the ICM process.

\section{Objectives}

This study ascertained the impact of the coastal management program implemented by a university in Village Looc, Mandaue City, Cebu, Philippines. The findings served as basis for program enhancement. 


\section{Methods}

This qualitative study utilized the descriptive design. It was conducted in Village Looc, Mandaue City, Cebu, Philippines. There were ten informants who were interviewed six months after the implementation of the coastal management program in April 2019. The coastal management program was called Save the Barangay (Village) Looc Mandaue City Bay. This coastal management program is a joint collaboration program between the Village Looc Council and UCLM. The researchers interviewed the informants for four consecutive Saturdays. Common themes were ascertained from the narratives of the informants.

Informant 1 is a 28-year old housewife and a resident of the village since birth. Her parents were originally from Camotes Island. Her mother decided to transfer to Mandaue City, Cebu to be with her second husband. Informant 1 pursued her studies and graduated high school through the Alternative Learning Scheme. She was formerly a Production Operator in Cebu Light Industrial Park, also known as MEPZ 3 in Lapu-Lapu City, Cebu. She quit the job after discovering that she was pregnant. Presently, she is a mother of two children. Her partner is a painter.

Informant 2 is a 70-year old single woman who hails from San Francisco, Camotes. She decided to live in Village Looc in 1962. She was hired as a house helper in Manila from 1971 to 1991. When she came back to the village, she worked in a hotel in Cebu City as a cook. With her savings, she was able to build a two-storey house in Sitio Paradise. But she has no electricity and no appliances at home.

Informant 3 is a 50-year old married woman who is also from San Francisco, Camotes. She used to work as a house helper, and later as a fashion accessory worker. She got married twice. She 
has ten children. Five of her children have finished high school. Her husband, 47 years old, is a tricycle driver.

Informant 4 is 28 years old. She is from Bantayan Island with a live-in partner and a 7-month old baby girl. The couple decided to transfer to the village due to her husband's work in Cebu City. She manages a store in her house. They use charcoal and butane for cooking. Although the couple has their own comfort room, the sea serves as the septic tank.

Informant 5 is a 21 -year old college student. His parents are fisherfolks and his parents manages a small seaweed plantation in Leyte. His parents would visit their house in Village Looc every November of the year. The house is two-storey with appliances but no comfort room. According to him, they use a communal toilet and the fecal matter goes directly to the sea.

Informant 6 is a 26-year old female resident who hails from Surigao. After high school, she came to Cebu to study a vocational program for two years. Currently, she is jobless. She lives with five relatives in the house.

Informant 7 is a 36-year old married teacher. She works in an elementary public school. Her husband is an electrician. She has been a resident of the village for 36 years.

Informant 8 is a 54-year old store owner in the village. He graduated from high school and a native of Bohol. He is married and has been a resident of the village for 25 years.

Informant 9 is 42 years old. She is a high school level vendor who hails from Esperanza, Camotes. She has 5 children and has been a resident of the village for 21 years. 
Informant 10 is a 49-year old jeepney driver with one child. He was born and raised in Medellin, Cebu. They have lived in Barangay Looc for 17 years now. During the interviews, he was staying at home due to Pneumonia while his wife sells food items for the family to survive. His only child is 17 years old and presently in Grade 9.

\section{Results and Discussion}

The interviews were conducted in four consecutive Saturdays. The following themes were formed.

\section{Garbage directly thrown at sea}

All informants admitted that they directly throw their garbage at sea. The location of their households makes it more accessible for them to throw it on waters. Informant 10 relates, "We do not have trash bins to segregate our trash. We place all solid wastes in plastics. Since we have a very small area at home, we throw the plastics directly at sea. Our food scraps are also thrown which feeds the fishes. I have created a hole on the floor of the dining area for this."

It was observed by the researchers that the area has a distinct foul odor. Solid wastes like plastic sachets were floating at sea. Informant 9 shares that the area was very clean when they were younger. In fact, the sand was white and children would swim in the area. Informant 9 laments, "Nowadays, people are afraid to swim in the coastal areas. Aside from solid wastes, we prohibit our children to swim so that they could avoid skin allergies and other disease conditions."

But Informant 3 finds this as a problem as well. During high tide, the floating solid wastes would enter their houses, since the houses are directly built over the waters. She said, "We are 
punished by nature for our acts. Our trash goes inside our households, not to mention that odor is very evident when the seas are on low tide."

\section{The sea as comfort room}

The researchers have observed that fecal matter was floating on the waters. This has led the researchers to ask questions regarding human waste disposal. Informant 1 shares, "We do not have a comfort room in our house. My partner has created a hole at the center of the house where we urinate and defecate. The communal toilet which was created by the local government unit is too far from this area. My family has been accustomed to "poo" and "pee" inside the house, which is more convenient for us. Besides, the sea creatures will consume our fecal matter."

Informant 4 has the same sentiments. She relates, "I am tempted to swim. But whenever I walk with my partner at the sea shore, I have noticed skin allergies which is very difficult to manage. Although we have prohibited kids to swim, these kids cannot help but be tempted to enjoy the waters. We are also concerned if these kids accidentally drink the sea water."

\section{Coastal Management Program is helping our environment}

The coastal management program started in April 2019 and will end by April 2020. This program is called Save the Barangay Looc Mandaue City Bay. The program is a partnership between the Barangay Looc Council and UCLM. According to the informants, they are happy that faculty, staff, alumni and students are participating in the clean-up of the coastal area. Informant 8 recalls, "The trash near the sea shore was 3-4 meters high. Now, you can see the white sand and the waters have turned clear. Six months after the program, we have seen a decrease in the number of 
floating solid wastes. The residents are also encouraged to stop throwing plastics and other solid wastes."

Informant 6 shares, "We love the program because it helps our village and we are provided with rice. The program is so unique because one kilo of rice is given for every one kilo of trash that we collect. Rice is important for us because it gives us source of food and nutrition. That's why most of us also participate in the collection of solid wastes. The more wastes collected, the more rice we receive."

\section{Clamor to extend the coastal management program}

The program will end on April 2020. The community residents are requesting for the extension of the program. They have appreciated the help of UCLM in maintaining the cleanliness and orderliness of the village. Informant 7 states, "The participants of UCLM every first Saturday of the month is really big. With the number of participants that they send, the village knows that a lot of solid wastes can be collected."

From the secondary data collected from UCLM, a total of 11,290 kilos of solid wastes were collected from April 2019 to January 2020 . This has significantly changed the landscape of the coastal area. The chart below presents the solid wastes collected every month for the last 10 months. The chart reveals that the number of solid wastes collected has declined since November 2019 with peak months on September and October 2019.

Informant 5 also shared that as a student, he now appreciates the value of consistent clean-ups in the coastal area. He said, "I have joined the clean-ups many times, and I have felt a certain degree of achievement and satisfaction from the advocacy. My friends and classmates have participated as well. As soon as you 
see an area clean, you yearn to see the entire village to attain such cleanliness as well."

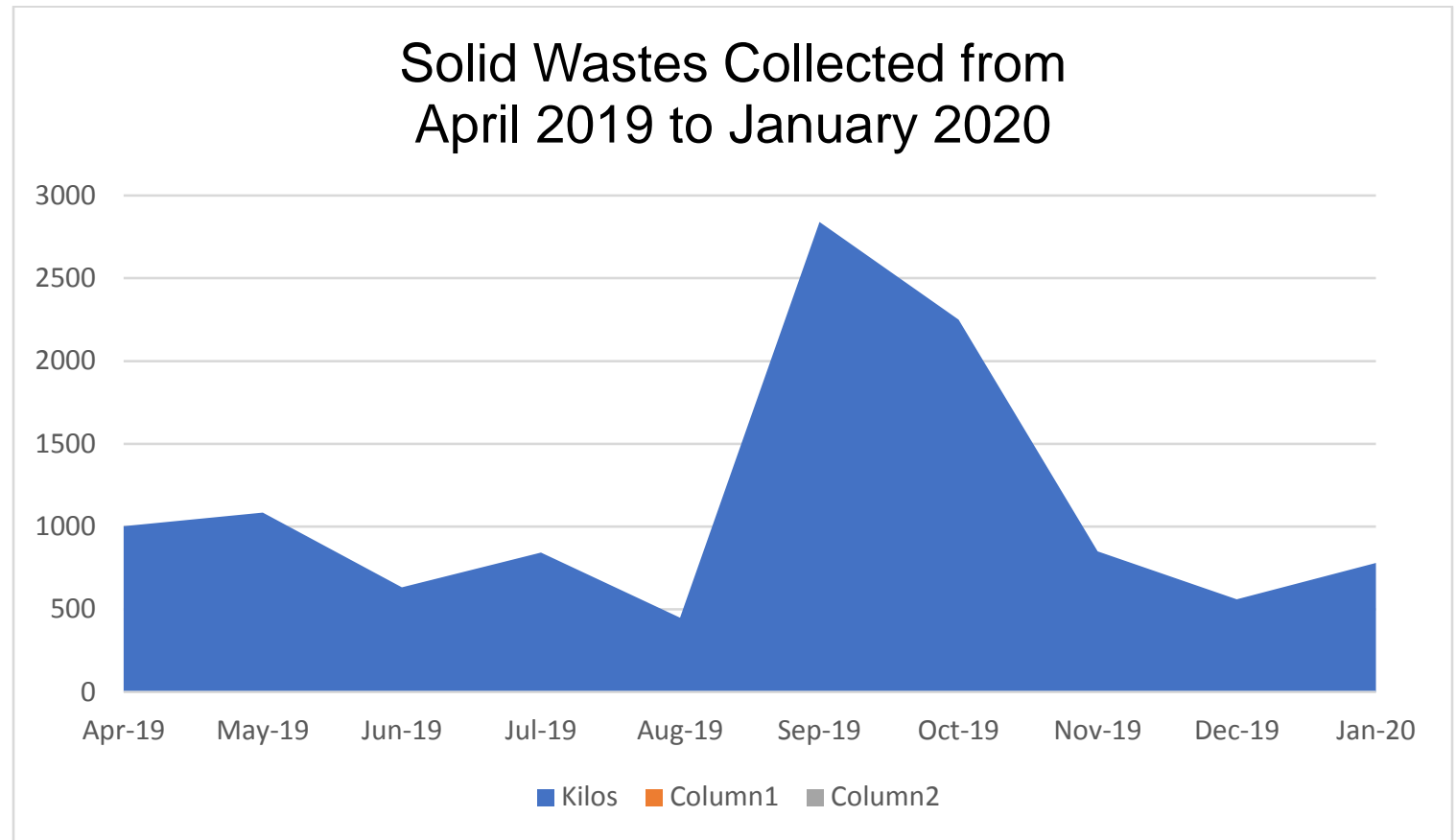

\section{Conclusion}

This study reveals the impact of the Save the Barangay Looc Mandaue City Bay, a coastal management program by UCLM which commenced on April 2019. The residents were satisfied with the program and find this beneficial to their village. The residents are also yearning for the extension of the program.

\section{Literature Cited}

Amparado, M. A. P., Camayra, M. T., Dorio Jr., P. A., \& Patindol, D. B. (2017). Sustainable Community Extension Programs for Village Looc, Mandaue City, Cebu, Philippines: The 8th Year Re-assessment. IAMURE, 102.

Amparado, M. A. P. \& Colonia, G. E. (2020). Community Needs Assessment of Village Opao, Mandaue City, Cebu, 
Philippines. Cebu Journal of Teacher Education, 1(1), 83100.

Amparado, M. A. P., Pinote, L. A. \& Hinoguin, J. F. (2020). Corporate Social Responsibility: Practices, Benefits \& Challenges of MBA Students. Cebu Journal of Business \& Accountancy, 2(1), 88-100.

Pauly, D. (1989). Coastal area management in Southeast Asia: policies, management strategies, and case studies (Vol. 2). WorldFish.

Perez, V. A., \& Cabrera, C. D. (2013). Impact of Coastal Clean-Up to Beneficiaries and Proponents: Basis for Community Extension Enhancement Program. Educational Research International, 2(1), 1-6.

Pollnac, R. B., \& Pomeroy, R. S. (2005). Factors influencing the sustainability of integrated coastal management projects in the Philippines and Indonesia. Ocean \& coastal management, 48(3-6), 233-251.

Robbins, S. P. \& Coulter, M. (2011), Management, $6^{\text {th }}$ edition. Singapore: Pearson Education Asia Pte. Ltd.

Wyles, K. J., Pahl, S., Holland, M., \& Thompson, R. C. (2017). Can beach cleans do more than clean-up litter? Comparing beach cleans to other coastal activities. Environment and behavior, 49(5), 509-535. 